\title{
A NEW BARE-SOIL INDEX FOR RAPID MAPPING DEVELOPING AREAS USING LANDSAT 8 DATA
}

\author{
S. Li*, X. Chen \\ Shenzhen Municipal Information Center of Land Resource, Urban Planning and Real Estate, 8009 Hongli Road \\ Shenzhen, P.R. China \\ suitsinglee@gmail.com; xueye31@163.com
}

\section{Commission IV, ICWG (IV/II/VIII)}

KEY WORDS: Tasseled cap transformation, Normalized difference bareness index, Logical combination, Landsat 8

\begin{abstract}
:
One of the most basic classification tasks is to distinguish bare-soil areas from urban region. Bare-soil plays an important role in the ecosystem. It could be the reason of dust storms and the indicator of urban expansion. It is also important to monitor the bare-soil areas, but there was no good idea to automatically extraction bare-soil areas using existing method. In this work, a new bareness index $(B I)$ has been developed and applied to map developing region in Pearl River Delta using Landsat OLI/TIRS data in 2013. The $B I$ based on the logical combination of the Tasseled Cap transformation (TCB) and Normalized Difference Bareness Index (NDBaI). Results show that the $B I$ not only has a good effect on the enhancement of bare soil information, but also on the inhibition of the background information, and improve the accuracy of detection. The results of this study could be of scientific and practical merits in regional remote sensing monitoring and improve the accuracy of land use classification.
\end{abstract}

\section{INTRODUCTION}

Land use and land cover change (LUCC) is regarded as the single most important variable of global change affecting ecosystems with an impact on the environment that is at least as large as that associated with climate change (Vitousek, 1994; Skole, 1994). So, gaining a better understanding of the ways that land cover practices evolve is a primary concern for the global change research community (Southworth, 2004). Over recent years, scholars have increasingly turned to remotely sensed data to improve the accuracy of datasets that describe the geographic distribution of land cover at different scales (De Fries, et al., 1998). Considerable efforts have gone into simplifying the process of automatically mapping land covers, such as using remote sensing feature indexes (Zha, et al., 2003). Researchers have developed many indexes based on the different land surface types, commonly used are Normalized Difference Vegetation Index (NDVI), Normalized Difference Snow Index (NDSI), Normalized Difference Water Index (NDWI), and Normalized Built-up Index (NDBI) and so on. These methods have been validated in the researches of land cover classification, for example, the use of NDVI data for land cover classification of vegetation types has become increasingly successful (Hansen, et al., 2000; Azzali and Menenti, 2000).

Bare-soil plays an important role in the ecosystem. It could be the reason of dust storms (Chen, 2004) and the indicator of urban expansion. It is also important to monitor the bare-soil areas, but there was no good idea to automatically extraction bare-soil areas using existing method. In the past, the most common are density slice using single or multiple bands and multispectral classification, both the method of supervised and unsupervised (e.g. ISODATA-unsupervised classification, principal components analysis (PCA), tasseled cap transformation (TCB), maximum-likelihood supervised classification). The TCB was originally constructed for understanding the phenomena of crop development in spectral space with Landsat data. It is a useful tool for compressing spectral data into a few bands associated with physical scene characteristics. The tasseled cap transformation of Landsat data consists of six multispectral features; three of the six tasseled cap transform bands are often used: B (brightness, measure of soil), G (greenness, measure of vegetation) and $\mathrm{W}$ (wetness, interrelationship of soil and canopy moisture) (Ouma and Tateishi, 2006). B change a component is closely related to the bare-soil information extraction soil brightness index.

Southworth (2004) find that the thermal infrared band (TIR) of Landsat TM measures the emission of energy from the Earth's surface and, as this is a function of the surface cover, it can be used as a determinant of land cover type based on the temperatures measured. According to this principle, Zhao \& Chen (2005) build a normalized difference bareness index (NDBaI) for mapping of the bare-soil areas from the satellite images. This index is based on the difference between strong reflection of TIR radiation and near total absorption of middle infrared (MIR) wavelengths by bare-soil (Chen, et al., 2006). It is effective in distinguishing bare-soil from similarly built-up and vegetation.

Sensors on Landsat satellites have been collecting images of the Earth's surface for nearly 40 years. These images play an irreplaceable role for earth observation. The successful launch of Landsat 8 on February 11, 2013 has made the research of theory and application based on OLI/TIRS image becomes hotspot at home and abroad. The Landsat 8 carries two instruments: the Operational Land Imager (OLI), collects image data for nine shortwave spectral bands (OLI1 OLI7, OLI9) over a $185 \mathrm{~km}$ swath with a $30 \mathrm{~m}$ spatial resolution for all bands except a $15 \mathrm{~m}$ panchromatic band (OLI8); the Thermal Infrared Sensor (TIRS), collects image data for two thermal bands with a

\footnotetext{
* Corresponding author.
} 
$100 \mathrm{~m}$ resolution over a $185 \mathrm{~km}$ swath. Quality of Landsat 8 data is superior to its predecessors (e.g. MSS, TM, ETM+), inclusion of a $15-\mathrm{m}$ resolution panchromatic band (OLI8), and two improved $100-\mathrm{m}$ spatial resolution thermal infrared band (TIRS10, TIRS11). Nevertheless, in the premise of the spatial resolution in the data band are not completely unified, thermal infrared bands lower spatial resolution will lead to a lack of information of features.

In this paper, we build a new methodology based on a logical combination of the two indices TCB and NDBaI for bare-soil areas mapping. This combined formulation is called the baresoil index $(\mathrm{BI})$. And it is applied within a Landsat 8 data (WRS2: Path/Row $=122 / 44$, acquired on August 9, 2013) covering part of the Pearl River Delta of P.R. China. The results are very promising following extensive empirical, ground measurements and statistical comparisons.

\section{DATA AND METHODOLOGY}

\subsection{Study area}

The Pearl River Delta (PRD) is located in Guangdong Province of South China, between $21^{\circ} 17.6^{\prime} \sim 23^{\circ} 55.9^{\prime} \mathrm{N}$ and $111^{\circ} 59.7^{\prime} \sim$ $115^{\circ} 25.3^{\prime}$ E. PRD has been selected as the study area considering its rapid urbanization in the past 30 years, which has been an important driver of China's economic growth and place for the country's growing integration into the global economy. PRD contains many cities and counties, including the city of Guangzhou, Shenzhen, Foshan, Nanhai, Dongguan, Zhongshan, Huizhou and Jiangmen, and the county of Boluo, Gaoming, Heshan and Xinhui (Figure 1), with a total population of 42.3 million, a total area of 41,698 square kilometres.

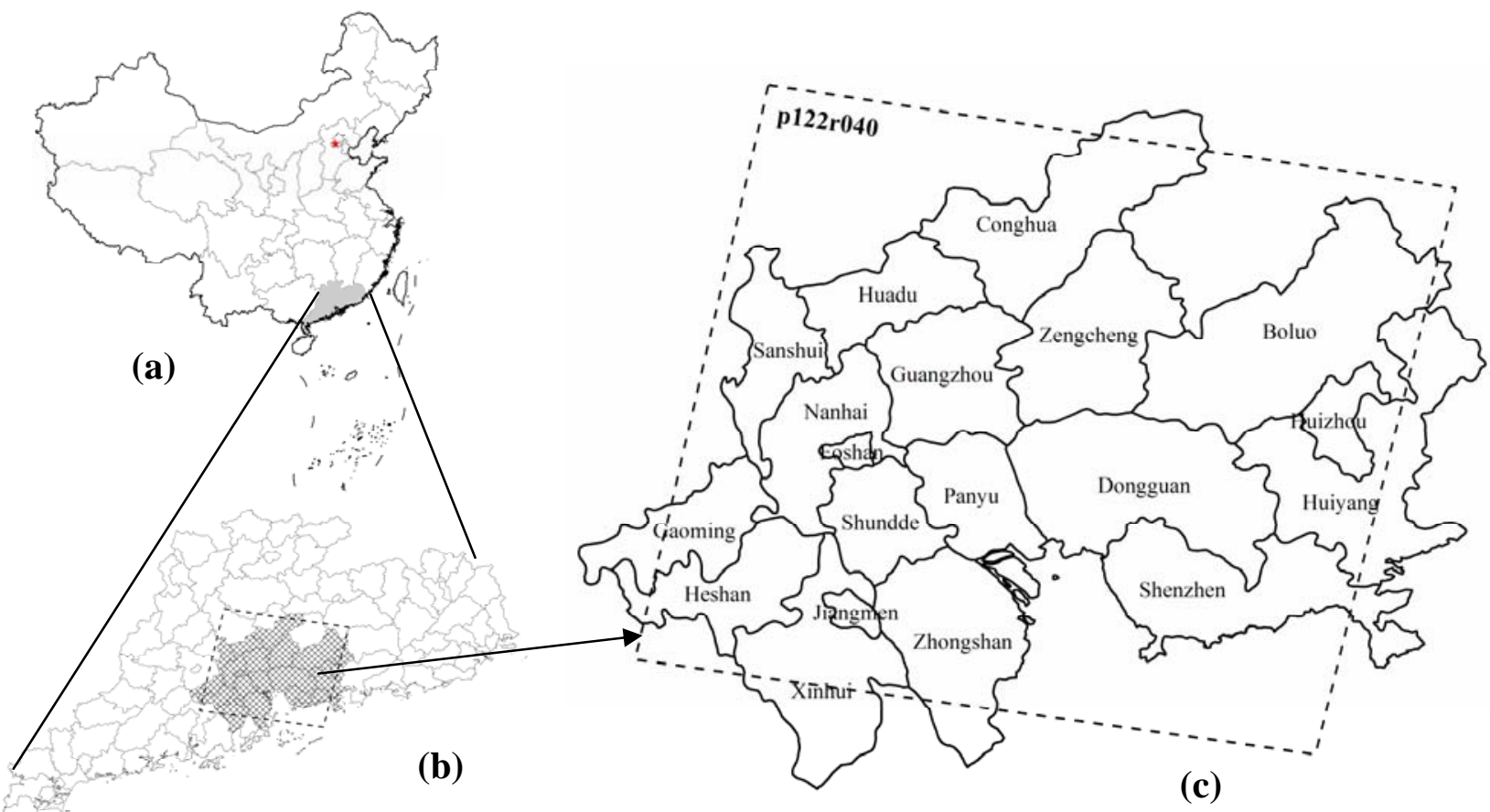

Figure 1. Location of Pearl River Delta. (a) Bound of China, (b) Administrative divisions of Guangdong Province and study area, and (c) Study area

\subsection{Data and Image Pre-processing}

The Landsat 8 carries two instruments: the Operational Land Imager (OLI), collects image data for nine shortwave spectral bands (OLI1 OLI9) over a $185 \mathrm{~km}$ swath with a $30 \mathrm{~m}$ spatial resolution for all bands except a $15 \mathrm{~m}$ panchromatic band (OLI8); the Thermal Infrared Sensor (TIRS), collects image data for two thermal bands (TIRS10, TIRS11) with a $100 \mathrm{~m}$ resolution over a $185 \mathrm{~km}$ swath (Irons et al., 2012).

A scene Landsat OLI/TIRS image covers an area of $185 \times 185$ $\mathrm{km}$, covering most areas in the PRD. The study data were taken from 9 August 2013 for Landsat 8 in a scene (path 122, row 044) of Level 1 (L1). And the data can be downloaded from the Center for Earth Observation and Digital Earth (CEODE, http://www.ceode.cas.cn/) or the Earth Resources Observation and Science Center (EROS, http://glovis.usgs.gov/).
OLI band data can be converted to Top Of Atmosphere (TOA) reflectance using reflectancerescaling coefficients provided in the product metadata file (MTL file). The following equation is used to convert DN values to TOA reflectance for OLI data as follows (USGS, 2013):

$$
\rho \lambda=\frac{M_{\rho} Q_{c a l}+A_{\rho}}{\sin \left(\theta_{S E}\right)}
$$

where:

$\rho \lambda=$ TOA planetary reflectance.

$M_{\rho}=$ Band-specific multiplicative rescaling factor from the metadata (REFLECTANCE_MULT_BAND_x, where $\mathrm{x}$ is the band number).

$A_{\rho}=$ Band-specific additive rescaling factor from the metadata (REFLECTANCE_ADD_BAND_x, where $\mathrm{x}$ is the band number). 
$Q_{\text {cal }}=$ Quantized and calibrated standard product pixel values $(\mathrm{DN})$.

$\theta_{S E}=$ Local sun elevation angle. The scene center sun elevation angle in degrees is provided in the metadata (SUN_ELEVATION).

The removal of method was performed by using software ERDAS IMAGINE 2013. To analyse the bare-soil areas changes in the study region, multi-temporal images were georeferenced to a common UTM coordinate system and resampled using the nearest neighbour algorithm with a pixel size of $30 \mathrm{~m}$ by $30 \mathrm{~m}$ for all bands except the TIR band. The RMSE of rectification was controlled less than 0.5 pixel.

\subsection{Tasseled Cap Brightness (TCB)}

The concept of tasseled cap transformation was originally constructed for understanding the phenomena of crop development in spectral space with Landsat MSS data. It is a useful tool for compressing spectral data into a few bands associated with physical scene characteristics . The tasseled cap transformation of Landsat TM or ETM+ consists of six multispectral features, three of the six tasseled cap transform bands are often used: B (brightness, measure of soil), G (greenness, measure of vegetation) and $\mathrm{W}$ (wetness, interrelationship of soil and canopy moisture). The Tasseled Cap transformation provides useful information for agricultural applications because it allows the separation of bare-soils from vegetated and wet soils. Research has produced three data structure axes that define the vegetation information content. B change a component is closely related to the bare soil information extraction soil brightness index for Landsat, the computational model is as follows (Crist et al, 1986; Jensen, 1996):

Brightness $=0.3037 *$ OLI $2+0.2793 *$ OLI $3+0.4743 *$ OLI $4+$ $0.5585^{*}$ OLI $5+0.5082 *$ OLI $6+0.1863 *$ OLI 7

Greenness $=-0.2848 *$ OLI $2-0.2435^{*}$ OLI $3-0.5436 *$ OLI $4+$ $0.7243 *$ OLI $5+0.0840 *$ OLI $6-0.1800 *$ OLI 7

Wetness $=0.1509 *$ OLI $2+0.1973 *$ OLI $3+0.3279 *$ OLI $4+$ $0.3406 *$ OLI 5 - $0.7112 *$ OLI 6 - $0.4572 *$ OLI 7

where: $\mathrm{OLI}_{i}$ represents digital number value $(\mathrm{DN})$ of corresponding bands.

\subsection{Normalized Difference Bareness Index (NDBaI)}

Normalized Difference Bareness Index (NDBaI) was first introduced by Zhao \& Chen in 2004. This index is based on significant differences of spectral signature in the nir-infrared (OLI 6) between the bare-soil and the backgrounds. However, it showed little difference between built-up areas and bare-soil areas in OLI 6 (Figure 2) (Zhao \& Chen, 2004). Figure 2 suggests that further consideration of the visible may be necessary to determine the vegetation areas. In this work we propose to estimate the NDBaI by evaluating different NDBaIs based on the different spectral bands of Landsat. The computational models are as follows:

$$
\begin{aligned}
& \mathrm{NDBaI}_{1}=[\mathrm{OLI} 7-\mathrm{TIRS}] /[\mathrm{OLI} 7+\mathrm{TIRS}] \\
& \mathrm{NDBaI}_{2}=[\mathrm{OLI6}-\mathrm{TIRS}] /[\mathrm{OLI} 6+\mathrm{TIRS}] \\
& \mathrm{NDBaI}_{3}=[\mathrm{OLI5}-\mathrm{TIRS}] /[\mathrm{OLI} 5+\text { TIRS }] \\
& \mathrm{NDBaI}_{4}=[\mathrm{OLI} 4-\mathrm{TIRS}] /[\mathrm{OLI} 4+\mathrm{TIRS}] \\
& \mathrm{NDBaI}_{5}=[\mathrm{OLI} 3-\mathrm{TIRS}] /[\mathrm{OLI} 3-\mathrm{TIRS}] \\
& \mathrm{NDBaI}_{6}=[\text { TOA6 }- \text { TOA5] } /[\text { TOA6 }+ \text { TOA5 }] \\
& \mathrm{NDBaI}_{7}=[\mathrm{TOA} 5-\mathrm{TOA} 4] /[\mathrm{TOA} 5+\mathrm{TOA} 4]
\end{aligned}
$$

where: $O L I_{i}$ represents digital number value (DN) of corresponding bands, TIRS represents digital number value (DN) of
TIRS10 for OLI, $T O A_{i}$ represents TOA reflectance of corresponding bands.

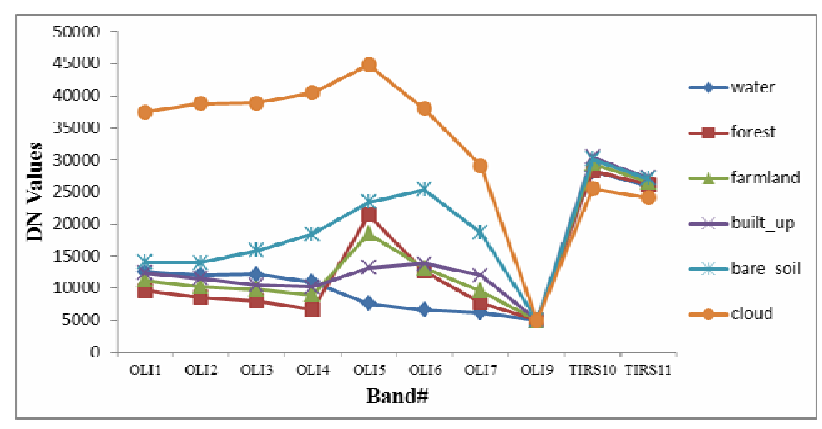

Figure 2. Spectral profiles of six typical land covers in the study area

\section{APPLICATION AND RESULTS}

\subsection{Methodology for Test Case Using Shekou Peninsula}

Firstly, we performance of each of the NDBaIs and TCB by comparing results from OLI data for Shekou Peninsula in Shenzhen, for different background of the bare-soil areas with interesting features/characteristics. The Shekou Peninsula was chosen for the test because coastal reclamation has been carried out along the coastal areas near Shenzhen, China in a large scale since 1980 s by dumping fill materials over the marine mud at the sea bottom (Huang, et al., 2007). In addition, the authors have a good physical knowledge of the peninsula.

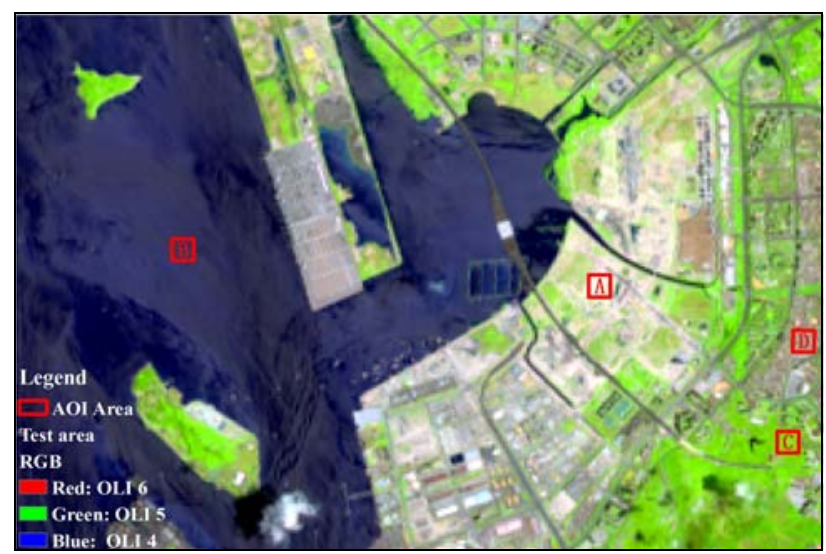

Figure 3. The false color image $(\mathrm{R}(6) \mathrm{G}(5) \mathrm{B}(4))$ of test area

A comparison between the TCB and the $\mathrm{NDBaI}_{1-7}$ maps are presented in Figure 4(a) and 4(b)-4(h) derived from OLI data of Aug. 9, 2013. TCB (Figure 4 (a)) $\mathrm{NDBaI}_{1}$ (Figure 4(b)), and $\mathrm{NDBaI}_{2}$ (Figure 4(c)) results increase the bare-soil very well, comparing the entire scene, the bare-soil is well delineated with bright pixels. $\mathrm{NDBaI}_{3}$ (Figure 4(d)) results increase the baresoil very well, but the vegetation aslo delineated with bright pixels too, this method does not apply southern humid areas of bare soil information extraction. A visual comparison of NDBaIs results shows that $\mathrm{NDBaI}_{1}$ (Figure 4(b)) and $\mathrm{NDBaI}_{4}$ (Figure 4(e)) present a nearly similar output. $\mathrm{NDBaI}_{6}$ (Figure $4(\mathrm{~g}))$ results also increase the bare-soil very well, but the water body aslo delineated with bright pixels too, this method does not apply southern humid areas of bare soil information extraction too. From the visual point of view, the tasseled cap transformation (TCB), $\mathrm{NDBaI}_{1}, \mathrm{NDBaI}_{2}$ and $\mathrm{NDBaI}_{4}$ have the better extraction results than others. 

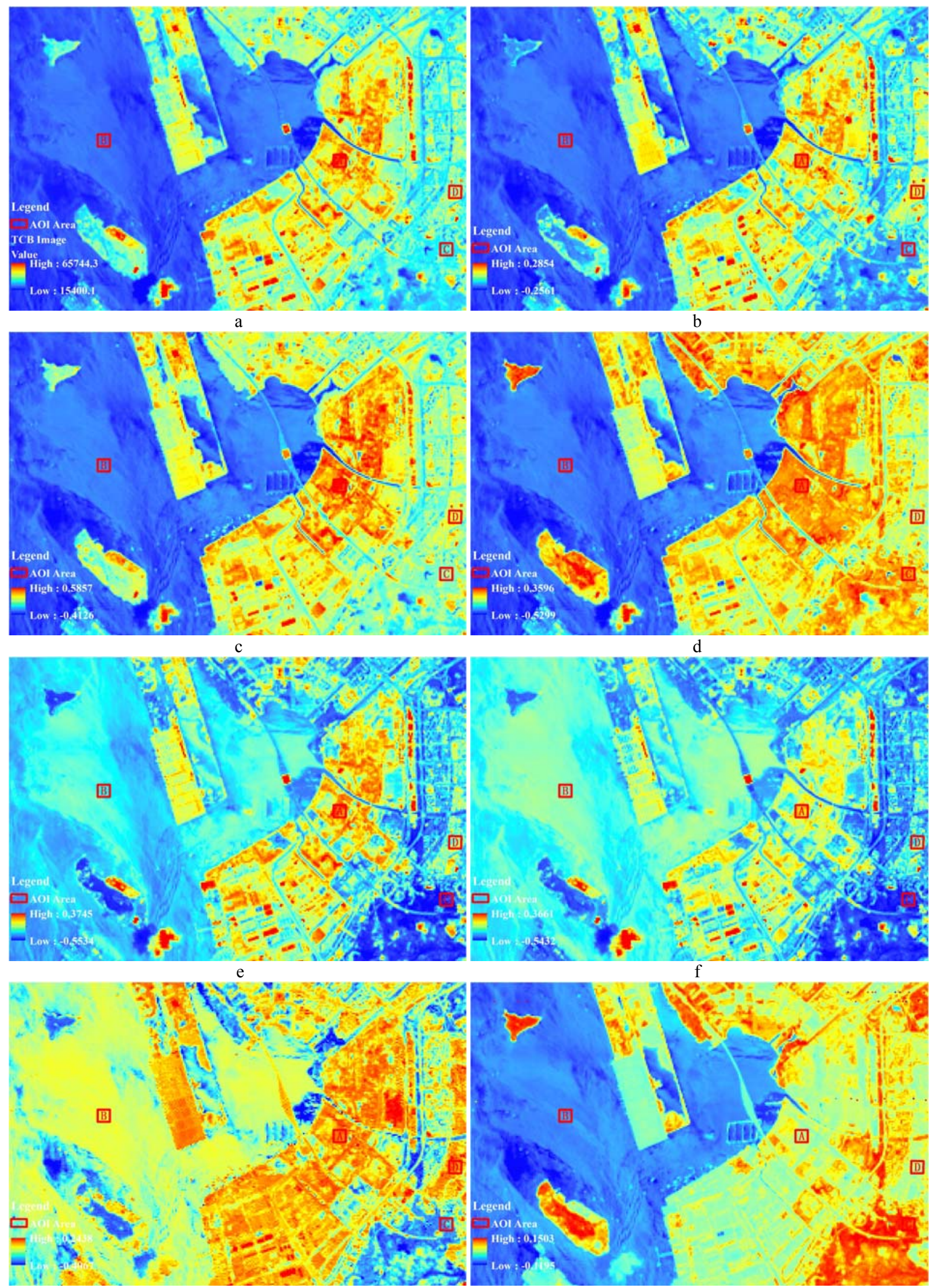

$\mathrm{g}$

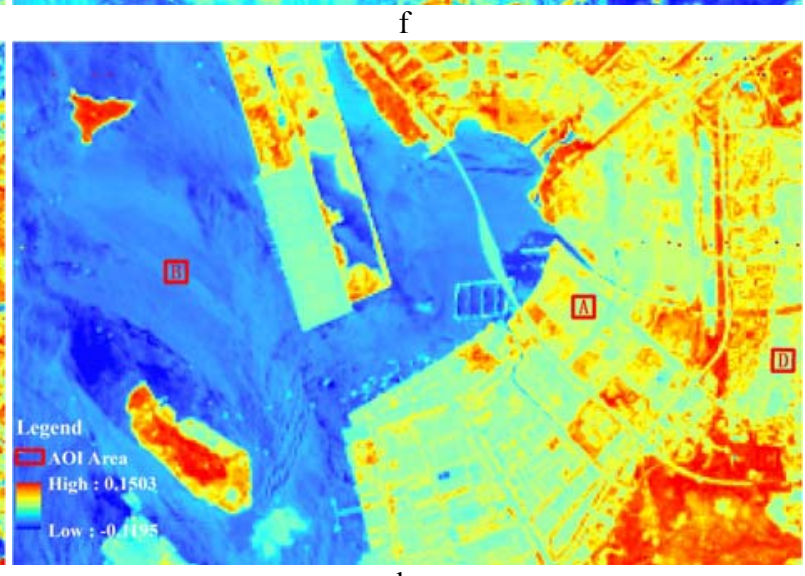

Figure 4. Results of TCB (a) and NDBaI1-7 (b h) for Shekou Peninsula in Shenzhen 


\subsection{Comparison of TCB with the NDBaIs Results}

To evaluate the significance of the results, we empirically analyzed the results of the NDBaIs. We selected unique sections of the test area: (i) bare-soil area (A); (ii) water body area (B); (iii) vegetation area (C); and (iv) built_up area (D). In figure 3 (false color composite of OLI bands 6,5 and 4 ), sections $\mathrm{A}, \mathrm{B}, \mathrm{C}$ and $\mathrm{D}$ of the test area are marked out. Calculating the contrast value $(\mathrm{C})$ between bare-soil with the background to quantitative evaluation of the difference between the NDBaIs. The computational model as follows:

$$
C=|\bar{a}-\bar{b}|
$$

where: $C$ is contrast value, $\bar{a}$ is the mean value of bare-soil area, $\bar{b}$ is the mean value of background areas.

Table 1 Mean values of NDBaIS bands and the contrast value $(C)$ between bare-soil area with the background areas

\begin{tabular}{cccccccc}
\hline & bare-soil & water & vegetation & built_up & $C_{-}$ab & $C_{\_}$ac & $C_{-}$ad \\
\hline $\mathrm{TCB}^{*}$ & 0.6105 & 0.1146 & 0.2453 & 0.3256 & $\mathbf{0 . 4 9 5 9}$ & 0.3653 & $\mathbf{0 . 2 8 4 9}$ \\
$\mathrm{NDBaI}_{1}$ & -0.2437 & -0.6047 & -0.5092 & -0.3746 & 0.3610 & 0.2655 & 0.1309 \\
$\mathrm{NDBaI}_{2}$ & -0.0943 & -0.5763 & -0.4070 & -0.3230 & 0.4819 & 0.3127 & 0.2286 \\
$\mathrm{NDBaI}_{3}$ & -0.1317 & -0.5489 & -0.1796 & -0.3455 & 0.4172 & 0.0479 & 0.2138 \\
$\mathrm{NDBaI}_{4}$ & -0.2519 & -0.4730 & -0.5950 & -0.4184 & 0.2212 & 0.3431 & 0.1665 \\
$\mathrm{NDBaI}_{5}$ & -0.3183 & -0.4159 & -0.5371 & -0.4276 & 0.0976 & 0.2187 & 0.1093 \\
$\mathrm{NDBaI}_{6}$ & 0.0476 & -0.1115 & -0.3552 & 0.0382 & 0.1592 & 0.4028 & 0.0094 \\
$\mathrm{NDBaI}_{7}$ & 0.1648 & -0.2291 & 0.7296 & 0.1363 & 0.3939 & $\mathbf{0 . 5 6 4 8}$ & 0.0285 \\
\hline
\end{tabular}

Note: TCB $^{*}$ is the normalized values of TCB iamge.

Table 1 shows that TCB gave the best results in inhibition of influence from water bodies and buildings on bare-soil, followed by $\mathrm{NDBaI}_{2}$ and $\mathrm{NDBaI}_{3}$. $\mathrm{NDBaI}_{7}$ gave the best results in inhibition of influence from vegetation, followed by $\mathrm{NDBaI}_{6}$ and TCB. $\mathrm{NDBaI}_{2}$ gave the results in inhibition of the background surface features are not the best, but the contrast between the average value is more suitable for bare soil to extract information in complex environments.

From all the above results, it is consistently observed that TCB and $\mathrm{NDBaI}_{2}$ gave the best results.

\subsection{Bare-soil Index (BI)}

Following empirical analysis of the results, TCB gave better results than either of the NDBaIs. However, the problem of a clearly defined bare-soil area is persistent in both the results; that is, crispness does not imply higher accuracy and fuzziness does not necessarily mean lower accuracy. Striking a balance between these two observations is a way forward to accurate bare-soil area detection from remote sensing data. A new baresoil Index (BI) has been proposed that combines the TCB and $\mathrm{NDBaI}_{2}$ to accurately delineate the bare-soil. The model as follows:

$$
B I=f\left(\overline{T C B}, \overline{\mathrm{NDBaI}_{2}}\right)
$$

where: $f$ denotes a function, $\overline{T C B}$ is the normalized values of TCB iamge, and $\overline{\mathrm{NDBI}_{2}}$ is the normalized values of $\mathrm{NDBaI}_{2}$ iamge.

\subsection{BI results of study area}

The results of BI based on Shekou Peninsula is illustrated in figures 5 for the Landsat OLI, respectively. The results show bare-soil area isolation from the rest of the scenes. Figures 5 for the Landsat OLI showing the bare soil can be well distinguish with the background, which was fuzzily represented before by the TCB and NDBaIs (figure 4), are now perfectly isolated.

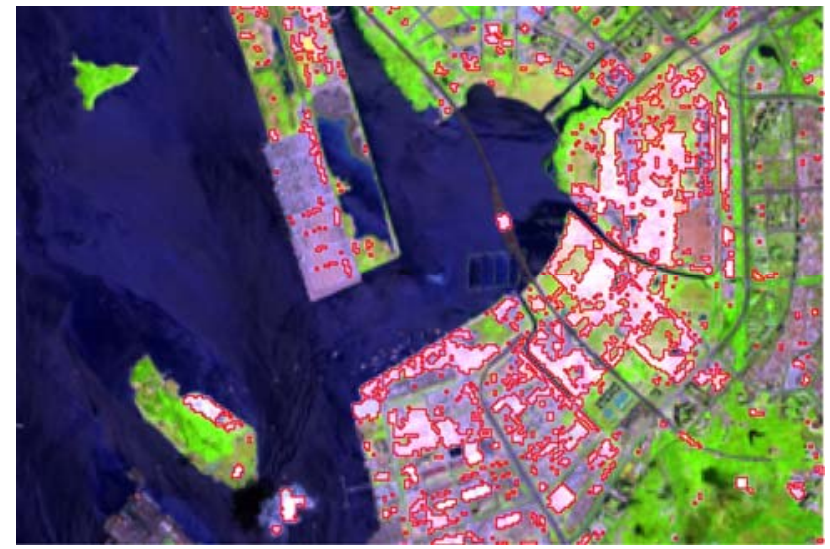

Figure 5. The BI results of study area

\section{CONCLUSION}

Bare-soil plays an important role in the ecosystem. It could be the reason of dust storms and the indicator of urban expansion. It is also important to monitor the bare-soil areas, but there was no good idea to automatically extraction bare-soil areas using existing method. In this paper, we build a new methodology based on a logical combination of the two indices TCB and $\mathrm{NDBaI}_{2}$ for bare-soil areas mapping. This combined formulation is called the bare-soil index (BI). And it is applied within a Landsat 8 data (WRS2: Path/Row $=122 / 44$, acquired on August 9, 2013) covering part of the Pearl River Delta of P.R. China. The results are very promising following extensive empirical, ground measurements and statistical comparisons.

\section{REFERENCES}

Azzali, S., Menenti, M., 2000. Mapping vegetation-soil-climate complexes in southern Africa using temporal Fourier analysis of NOAA AVHRR NDVI data, Int. J. Remote Sens., 21(5), pp.973-996. 
Chen, X. L., Zhao, H. M., Li, P. X., Yin, Z. Y., 2006. Remote sensing image-based analysis of the relationship between urban heat island and land use/cover changes, Remote Sensing of Environment, 104(2), pp.133-146.

Chen, W., Liu, L., Zhang, C., Wang, J., Wang, J., Pan, Y., 2004. Monitoring the seasonal bare soil areas in Beijing using multitemporal TM images, Geoscience and Remote Sensing Symposium, pp.3379-3382.

Crist, E. P., Cicone, R. C., 1984. A physically-based transformation of Thematic Mapper Data-The TM Tasseled Cap, IEEE Transactions on Geoscience and Remote Sensing, GE-22(3), pp. 256-263.

Crist, E. P., Kauth, R. J., 1986. The tasseled cap de-mystified, Photogrammetric Engineering and Remote Sensing, 52(1), pp: 81-86.

De Fries, R. S., Hansen, M., Townshend, J. R. G., Sohlberg, R., 1998. Global land cover classifications at $8 \mathrm{~km}$ spatial resolution: the use of training data derived from Landsat imagery in decision tree classifiers. Int. J. Remote Sens., 19(16), pp.3141-3168.

Hansen, M., De Fries, R. S., Townshend, J. R. G., Sohlberg, R., 2000. Global land cover classification at $1 \mathrm{~km}$ spatial resolution using a classification tree approach, Int. J. Remote Sens., 21(6), pp.1331-1364.

Huang, J., Huang, R., Jiao, J. J., Chen, K., 2007. Speciation and mobility of heavy metals in mud in coastal reclamation areas in Shenzhen, China, Environmental Geology, 53(1), pp.221-228.

Kauth, R. J., Thomas, G. S., 1976. The tasseled cap-a graphic description of the spectral-temporal development of agricultural crops as seen by Landsat, In Proceedings of the Symposium on Machine Processing of Remotely Sensed Data, Purdue University of West Lafayette, Indiana, pp. 4B-41-4B-51.
Skole, D. L., 1994. Data on global land-cover change: acquisition, assessment and analysis. In: Meyer W B, Turner B L, II(Eds.), Changes in land use and land cover: a global perspective (pp.437-471), Cambridge: Cambridge University Press.

Sobrinoa, J. A., Jiménez-Muňoza, J. C., Paolinib, L., 2004. Land surface temperature retrieval from LANDSAT TM 5, Remote Sensing of Environment, 90(4), pp.434-440.

Sospedra, F., Caselles, V., Valor, E., 1998. Effective wavenumber for thermal infrared bands-application to Landsat-TM, Int. J. Remote Sens., 19(11), pp.2105-2117.

Southworth, J., 2004. An assessment of Landsat TM band 6 thermal data for analyzing land cover in tropical dry forest regions. Int. $J$. Remote Sens., 25(4), pp.689-706.

Vitousek, P. M., 1994. Beyond global warming: ecology and global change. Ecology, 75(5), pp.1861-1876.

Wang, F., Qin, Z. H., Wang, Q. Q., 2012. A method of TM6 band pixel decomposition based on the earth surface types, Remote Sensing for Land \& Resources, 24(4), pp.54-59. (in Chinese)

Yang, L., Huang, C., Homer, C. G., Wylie, B. K., Coan, M. J., 2003. An approach for mapping large-area impervious surfaces: synergistic use of Landsat-7 ETM+ and high spatial resolution imagery, Canadian Journal of Remote Sensing, 29(2), pp.230-240.

Zha,Y., Gao, J., Ni, S., 2003. Use of normalized difference built-up index in automatically mapping urban areas from TM imagery, Int. $J$. Remote Sens., 24(3), pp.583-594.

Zhao,H. M., Chen, X. L., 2005. Use of normalized difference bareness index in quickly mapping bare areas from TM/ETM+. Geoscience and Remote Sensing Symposium, 3(25-29), pp.1666-1668. 